\title{
Usos da língua ucraniana entre imigrantes e seus descendentes no Paraná e sua tradução para o português'
}

\author{
Paulo Guérios \\ Doutor em Antropologia Social (Museu Nacional) \\ Professor da Universidade Federal do Paraná, \\ Curitiba, Paraná, Brasil \\ pguerios@ig.com.br
}

\begin{abstract}
Resumo Durante minha pesquisa entre os camponeses descendentes de ucranianos no Paraná, o aprendizado da língua ucraniana (uma língua eslava aparentada ao russo) impôs-se progressivamente como essencial para o desenvolvimento do trabalho. Se por um lado o domínio (mesmo que parcial) da língua falada facilitou minha inserção em campo e meu acesso a temáticas e a rituais familiares e religiosos, por outro o domínio do alfabeto cirílico e da língua escrita permitiu, por meio do trabalho sobre os arquivos da etnia, tematizar: as injunções políticas do uso de um dado registro vocabular da língua ucraniana por parte dos imigrantes que vieram ao Brasil; o significado de diversas categorias nativas e as leituras que elas possibilitam sobre a realidade vivida; a viabilidade da tradução ou da necessidade de manter-se um dado termo em sua língua original, assim como da contextualização das categorias nativas; e as problemáticas relativas à transliteração do alfabeto cirílico para o português.
\end{abstract}

Palavras-chave: tradução cultural, ucranianos-Brasil, análise de discurso.

\section{Introdução}

\begin{abstract}
A o propor uma reelaboração da tarefa da Antropologia Social BriA tânica na Marret Lecture de 1950, Evans-Pritchard defendeu que fosse enquadrada como uma das disciplinas das Humanidades, e não como uma ciência natural. Ele defendeu seu argumento aproximando a tarefa do antropólogo da tarefa do tradutor, argumentando da seguinte forma:
\end{abstract}

Uma terceira, e para mim a mais importante questão, é de caráter metodológico: se a antropologia social, apesar de toda a sua desconsideração atual acerca da história, não é ela mesma um tipo de historiografia. Para responder a essa questão nós temos antes que observar o que o antropólogo faz. Ele vai viver por alguns meses ou anos com um povo primitivo. Ele vive entre eles tão intimamente quanto possível, e aprende a falar sua língua, a pensar com seus conceitos e a sentir com seus valores. Ele então revive as experiências criticamente e interpretativamente de acordo com

1. Uma versão anterior deste artigo foi apresentada no Grupo de Trabalho sobre Tradução Cultural da 26a Reunião Brasileira de Antropologia da ABA. Agradeço às coordenadoras do GT, Clarice Cohn e Priscila Faulhaber, e aos seus participantes pelo estímulo para sua escrita e publicação, assim como pelos comentários críticos quando de sua apresentação. 
as categorias conceptuais e os valores de sua própria cultura e em termos do corpo geral de conhecimento de sua disciplina. Em outras palavras, ele traduz de uma cultura em outra cultura. (Evans-Pritchard, 1950, p. 22)

A tarefa da Antropologia parte de uma tradução cultural, diz Evans Pritchard, para depois, auxiliada pelo estudo da estrutura social de uma sociedade, emprestar à vida nesta sociedade uma inteligibilidade cultural e uma inteligibilidade sociológica. Até que ponto, no entanto, a tradução serve como metáfora para a tarefa de um antropólogo? Seria realmente possível "reviver as experiências de uma sociedade com as categorias conceptuais de outra", como propõe Evans-Pritchard? E seria realmente essa a tarefa do antropólogo, afinal?

O presente artigo propõe uma reflexão acerca da tarefa da tradução e da tarefa do antropólogo a partir de meu trabalho com os arquivos da imigração ucraniana para o Brasil e de meu trabalho de campo entre os camponeses descendentes desses imigrantes, que realizei na cidade de Prudentópolis (PR) ao longo de 2003 e início de 2004. Os ucranianos² falam uma língua própria, de origem eslava, próxima ao russo e ao polonês, e utilizam o alfabeto cirílico. Entre os descendentes desses imigrantes que vivem hoje no Paraná, muitos ainda utilizam a língua ucraniana correntemente entre si para tratar de assuntos familiares e religiosos, e mesmo entre os que não dominam a língua certas expressões e categorias ainda são amplamente utilizadas no cotidiano.

Ao iniciar minha pesquisa entre esses camponeses, eu desconhecia totalmente sua língua. Ao longo de meu trabalho, no entanto, o seu domínio, ao menos instrumental, impôs-se como uma necessidade incontornável: além de meu interesse em explorar cuidadosamente os arquivos disponíveis em língua nativa, o fato de ter um domínio básico do vocabulário ucraniano facilitava o acesso a assuntos e dinâmicas que geralmente ficam restritos a quem é da etnia, pessoas enquadradas por esses camponeses na categoria nach lhude (наш льуди, "nossa gente"). ${ }^{3}$
Para discutir a tarefa da tradução e sua possível aproximação com a tarefa do antropólogo, optei por descrever de forma tentativa algumas experiências no contato com a língua ucraniana e meus esforços para verter trechos de textos do ucraniano para o português. Inicio abordando minhas primeiras tentativas de tradução, para depois explicar como trabalhei com as categorias do ucraniano em minha tese e como, a partir desse esforço, percebi a importância para a análise de outros fatores relativos à linguagem - caso da citação de línguas estrangeiras por parte dos nativos e do uso de diferentes alfabetos na escrita.

\section{A procura de um registro para a tradução}

Minha principal tarefa ligada ao uso da língua ucraniana relacionou-se à exploração dos relatos escritos que alguns migrantes deixaram, sob diferentes formas, acerca de sua vinda ao Brasil. Havia entre eles relatos autobiográficos, depoimentos escritos para jornais da etnia, cartas enviadas para migrantes que se dirigiram a outros países e relatórios de religiosos ou membros da intelligentsia acerca de suas atividades no Paraná.

A primeira questão no uso desses escritos dizia respeito à tarefa de tradução dos trechos que eu citaria na tese. Os tradutores de textos literários utilizam várias estratégias que eu poderia emular para solucionar meu problema, das quais destacarei duas.

Os textos estavam escritos em uma língua que deixou de existir: na Ucrânia, a língua ucraniana falada atualmente sofreu várias alterações por causa do contato constante com a língua russa, imposto pelo governo de Moscou nos anos de existência da União Soviética (entre 1917 e 1991); no Brasil e em outros países da diáspora ucraniana, décadas de contato com as línguas locais também alteraram o idioma ucraniano falado no fim do século XIX. ${ }^{4}$ A primeira solução seria destacar o caráter histórico da língua em que os

\footnotetext{
2. Ao vir para o Brasil, os ucranianos referiam-se a si próprios como "rutenos", que era o nome dado pela hierarquia católica aos povos eslavos de religião uniata (de rito bizantino, mas submetidos à autoridade do papa romano). Neste texto, para efeito de simplificação, utilizarei apenas a denominação "ucranianos". Essa denominação foi adotada de fato pelos próprios rutenos apenas após 1915, por causa do forte movimento nacionalista que ocorreu em seu país de origem durante a Primeira Guerra Mundial.
}

3. Entre eles, posso citar a participação em certos rituais, como as koliadê (Коляди, canções sacras cantadas em visitas entre os camponeses na época de Natal), ou mesmo a compreensão de trechos de diálogo em ucraniano que emergiam em meio a nossas conversas, levadas a cabo em português.

4. Essas mudanças aparecem também no corpus de textos utilizados para análise em meu trabalho, visto que relatos mais recentes já incorporam palavras e estruturas do português. Nos textos escritos a partir da década de 1930, surgem diversas palavras aprendidas nos momentos de interação com os brasileiros, em um início de processo de "pidginização" das duas línguas. Palavras como farêne [farinha], fazendéiriu [fazendeiros], caróce [carroças] e vende [relativo a "vendas", com o sufixo do plural -e do ucraniano] indicam o surgimento de uma língua franca local, que passou a ser necessária após o estabelecimento de relações com os brasileiros que viviam nas colônias. As palavras que surgem nos relatos dizem respeito à adaptação aos alimentos locais (a mandz'iákova farêna), ao trabalho temporário ocasional para os fazendéiriu das vilas vizinhas e à negociação da erva-mate nas vênde, que depois eram buscadas pelas caróce de seus donos. 
depoimentos estavam escritos através do uso de uma linguagem mediadora, para passar ao leitor a sensação de estranhamento contida na leitura dos textos originais.

Essa estratégia foi utilizada pelo tradutor Mauro Gama, que, ao traduzir recentemente poemas renascentistas de Michelangelo para o português, optou por utilizar o código camoniano, coetâneo às poesias do escultor italiano. Gama construiu, na verdade, uma releitura do italiano medieval no português medieval, vendo essa solução como a mais adequada para transmitir as intenções do poeta ao leitor do português contemporâneo.

A estratégia de usar exclusivamente termos do português quinhentista nessa tradução, contudo, parte de um pressuposto de homogeneidade entre as línguas coetâneas: é como se, por estarem afastadas no tempo, elas parecessem ao leitor atual mais próximas do que de fato eram em sua época. Adicionalmente, no caso da tradução de Gama, ela serve apenas para que o leitor contemporâneo do português sinta o mesmo estranhamento que o leitor italiano sente ao ler Michelangelo. Transpondo essa estratégia para o meu caso, utilizar um português novecentista para traduzir os originais ucranianos não contribuiria de forma alguma para transmitir ao leitor do português as informações de interesse constantes dos textos originais que eu tinha de traduzir.

Uma segunda opção seria alterar o português a partir do uso do ucraniano, deixando, como diz Walter Benjamin ([1923] 2000), que ele fosse afetado pela língua de meus textos originais. Uma possibilidade de fazê-lo seria mediante um processo que o poeta Haroldo de Campos chama de "transcriação" - captar a poética da escrita desses camponeses, cujo domínio da língua escrita era bastante precário, e tentar transmiti-la na língua portuguesa. Para isso, eu poderia utilizar um dialeto camponês do português. A melhor solução, no entanto, seria utilizar o português falado atualmente pelos descendentes desses migrantes, que contém elementos de uma língua créole. ${ }^{5} \mathrm{O}$ acento eslavo e mesmo a organização sintática da língua ucraniana estão muito presentes na fala do município. Ogliari (1999, p. 423-425) apresentou de forma estruturada, em sua tese, as várias interferências linguísticas do ucraniano que surgiram em suas entrevistas gravadas em português. Interferências de gênero ([a kwarta] em vez de "o quarto"), ([a pórtón] em vez de "o portão"); de número ([namoráde] em vez de "namorados"); de flexão verbal ([atakuvate] em vez de "atacar"), ([foisevate] em vez de "trabalhar com a foice" - "vate" é o sufixo do infinitivo ver- bal em ucraniano); de ordem ou posição das palavras na frase ([patós tchinha muitos ali] em vez de "tinha muitos patos ali”), ([nós mató i nas kapóéra bóa kaza téin] em vez de "tem boas casas nos matos e nas capoeiras"); no aspecto relacional ([éu vóu na Prudentópolis] em vez de "eu vou para Prudentópolis"); no apagamento de artigos ou cópulas ([pórcó móréu] em vez de "o porco morreu"), ([kénté djia] em vez de "o dia está quente"); e no aspecto verbal (estóu indo na Curitiba óntei) em vez de "fui para Curitiba ontem". Esta última opção seria a que, sem dúvida, mais aproximaria os relatos dos migrantes do português atual - afinal, esse português sincretizado com estruturas e palavras ucranianas é o mais próximo a que se pode chegar de tal objetivo.

Minha opção final, no entanto, foi não fazê-lo, e isso por dois motivos: em primeiro lugar, não creio que eu teria a habilidade necessária para tanto; essa tarefa exigiria um domínio das inflexões locais do português que dependeria de um contato muito mais prolongado com a fala nativa do que pude ter ao longo de um ano de trabalho de campo. Em segundo lugar, parte do material que eu estava utilizando já havia sido objeto de uma tradução para o inglês, feita por um pesquisador canadense de origem ucraniana que veio ao Brasil e que reuniu vários dos relatos no livro Under the Southern Cross. A collection of accounts and reminiscences about the ukrainian immigration in Brazil, 1891-1914 (Morski, 2000). Esse livro serviu como um alerta para o tipo de tradução que eu não deveria fazer. Preocupado com a legibilidade dos textos finais, Morski apagou a especificidade da linguagem utilizada pelos autores dos relatos. Trechos dos originais em que ocorriam longas digressões, releituras de cunho religioso dos eventos, redundâncias ou saltos entre diferentes temas apareciam linearizados na tradução, como se tivessem sido escritos de uma forma limpa e "coerente". O resultado final do trabalho, portanto, era uma versão dos relatos resumida e "reorganizada" pelo tradutor, que visava apenas à fluência do texto por parte do leitor final.

Ao linearizar os relatos sobre a migração, a tradução de Morski apagava as especificidades da reconstituição que cada migrante fazia acerca de sua experiência pessoal, que eram justamente o objeto de minhas preocupações em minha tese. Em que ordem os eventos eram apresentados? Quais as interpretações dadas pelos nativos a cada evento? Que palavras ou categorias específicas eram acionadas para dar conta de uma dada vivência que, enfim, era compartilhada entre todas as pessoas que passaram pela experiência da migração? Eu precisava detectar, por exemplo, se

\footnotetext{
5. Ao falar entre si, os camponeses mais idosos utilizam o contrário: um ucraniano mesclado de elementos do português. Um sacerdote local criou uma coluna no periódico religioso quinzenal da cidade em que ele utiliza essa linguagem créole para abordar de forma bem-humorada temas ligados ao calendário religioso. O personagem que "escreve" suas cartas à redação do jornal utiliza o alfabeto cirílico e mescla a semântica e a sintaxe das duas línguas.
} 
os migrantes empregavam recorrentemente determinadas categorias, como eles descreviam as novidades com que se deparavam ao longo de sua viagem, se empregavam palavras específicas que diziam respeito a situações que lhes eram familiares - ou seja, como eles reconstruíam a realidade que tinham vivido, lançando mão de uma linguagem que lhes era própria.

Todas as opções de tradução discutidas acima privilegiavam a legibilidade do leitor final em língua portuguesa. Contudo, essa postura implicava, ao mesmo tempo, um apagamento das particularidades do olhar nativo acerca dos eventos vividos. Ao orientar a tradução para o leitor final, o tradutor acaba eliminando de seu texto as idiossincrasias do texto original - e boa parte dos dados sociológicos que elas são capazes de revelar.

Ao discutir a tarefa do tradutor, Benjamin ([1923] 2000, p. 19-20) diz que ele deve encontrar "that intended effect upon the language into which he is translating which produces in it the echo of the original", ou seja, transmitir a intenção comunicativa do texto original, em vez de tomar como parâmetro a leitura na língua-alvo. Essa intenção comunicativa, no entanto, está eivada de elementos que encontram sua origem nas dinâmicas grupais, e que apenas uma análise comparativa de diversos textos pode revelar.

Deste modo, a necessidade de discutir as condições de produção de relatos acerca da migração e de transmitir ao meu leitor a mensagem que os originais desejavam transmitir aos leitores de ucraniano indicava-me que a melhor forma de tradução do ponto de vista literário não era necessariamente a que teria melhor rendimento para um trabalho que tinha por objetivo uma análise socioantropológica. Eu precisava de uma tradução que permitisse a meu leitor perceber o que interessava em relação ao meu problema de pesquisa: a presença do grupo a que cada autor pertencia "por trás" de cada texto, infletindo aquilo que essa pessoa poderia relembrar acerca do que vivenciou quando migrou para o Brasil. Para tanto, minha solução final foi traduzir para o português oficial moderno as sentenças que tinham um correspondente suficientemente claro em relação à língua ucraniana utilizada nos relatos e, para o restante, manter as categorias originais explicando seu significado cuidadosamente, ou utilizar uma tradução aproximada acrescida de notas explicativas acerca das imprecisões de tal tradução. No item a seguir, forneço vários exemplos de como levei a cabo tal tarefa.

\section{O uso de categorias da língua ucraniana entre os migrantes e seus descendentes}

A despeito de todas as diferenças existentes entre os relatos disponíveis acerca da vinda dos ucranianos para o Brasil, em vários momentos é possível detectar elementos comuns entre eles. Certos assuntos são recorrentes, eventos diferentes são muitas vezes descritos de maneira similar, e determinadas percepções acerca das novas experiências vividas nesse processo repetem-se em diferentes relatos.

Ao falar da vida na terra natal, no contexto do discurso sobre a vinda ao Brasil, por exemplo, as marcas da horiá (горя, "fardo") е da bidá (біда, "miséria") aparecem repetidamente em diferentes testemunhos. De outra parte, quando o assunto é o objetivo buscado com a migração, há palavras que estão também sempre presentes quando esses migrantes falam de sua experiência. São elas chtchástia (щастя, "felicidade" ou "alegria"), lipcha dólia (ліпша доля, "destino melhor"). Em seus depoimentos, pensar sobre a migração é seguir este contraste: de um lado, o passado na terra natal, a bidá, a horiá; de outro, o Brasil, a chtchástia, a lipcha dólia:

Nos primeiros dias de julho do ano de 1896 nos despedimos de uma vez por todas da aldeia em que nascemos, Ostalovetchi, no distrito de Peremechliane, expulsou-nos de nossa terra nativa a bidá, a pobreza e a horiá, buscando no então famoso Brasil uma lipcha dólia e a chtchástia. (Kobren, 1935)

Um dia durante as férias chegou meu pai e trouxe-nos uma novidade inesperada, que nós também viajaríamos para o Brasil, explicando-nos que tínhamos que ir para outro país procurar uma lipcha dólia e a chtchástia, pois aqui não há saída, é a bidá, e não há terra na qual trabalhar. (Cheutchuk, 1936)

Ao expressar-se dessa forma, os ucranianos não apenas dizem que era necessário mudar-se para escapar à pobreza e à falta de perspectivas; eles dizem isso sempre da mesma forma e com o uso das mesmas palavras. Esse contraste, assim, é muito mais do que uma mera informação ou um mero jogo de palavras: os ucranianos estruturam seus relatos a partir de um modelo pré-existente de compreensão dos eventos, um caminho conhecido e muitas vezes trilhado, que é empregado nas argumentações sem que seja anteriormente objeto de reflexão (Guérios, 2008).

$\mathrm{O}$ que chama a atenção nos relatos de viagem dos ucranianos ao Brasil é que as recorrências entre os discursos ocorrem mesmo sem intervenções externas. A presença ubíqua da oposição chtchástia $x$ bidá 
é um dos indicativos da existência de uma série de categorias compartilhadas entre eles que aproximaram suas percepções acerca da vinda para o Brasil.

As implicações da existência de categorias compartilhadas em cada configuração social tornaram-se uma questão clássica na disciplina da Antropologia, presente desde os textos fundadores de Durkheim [1912]1968) e Durkheim e Mauss ([1903] 1968). ${ }^{6}$

Exploremos um pouco mais o uso do contraste entre chtchástia e bidá. Essa oposição é um exemplo do que Sayad (1975, p. 63), em seu trabalho sobre os camponeses da Cabília, chama de uma "grande oposição mítica da tradição", ou seja, um esquema de percepção pré-codificado para a compreensão do mundo difundido entre os atores pertencentes a um dado grupo social. De fato, essa oposição é viva ainda hoje entre os descendentes dos migrantes, que lançam mão dela a todo o momento em suas interações cotidianas. "Chtchástia, zdoróvia" (felicidade e saúde) é a expressão utilizada em todos os votos de bem-estar - por exemplo, em datas festivas ou despedidas - e ao cumprimentar-se ou perguntar sobre pessoas que não se vê há algum tempo (como o "tudo bem?" em português). A nebulosa semântica ao redor da palavra bidá é mais complexa, englobando vários significados. Ela pode expressar "sofrimento", "miséria”, "pobreza", "infelicidade", todos esses elementos juntos ou mesmo o potencial de que eles ocorram no futuro. Nos depoimentos dos migrantes, ela é sempre acionada ao tratar da vida na terra natal e dos motivos da partida para o Brasil. Ao longo de meu trabalho de campo entre os descendentes desses migrantes, ouvi-a empregada de diferentes formas: como um verbo ("bidúie!" - sofre!/passa necessidade!), disse uma senhora a respeito de uma parente que tinha dificuldades financeiras para sobreviver); como uma interjeição (“bidá!” - tragédia!, sofrimento!), anunciou uma outra senhora antes de contar para uma irmã a respeito de um problema de família); como a síntese em uma palavra de uma situação difícil (em uma das cartilhas de língua ucraniana para crianças, um lagostim é capturado por um corvo, e sua situação é descrita apenas com essa palavra: "Vendo que bidá...", o que me foi traduzido por uma nativa como "vendo que a coisa estava preta...”).

Para transmitir ao meu leitor o olhar dos imigrantes acerca de sua vinda ao Brasil e de seu estabelecimento, vi assim que seria necessário discorrer cuidadosamente acerca do emprego de categorias como bidá ou chtchástia ao traduzir os textos que os utilizavam. Com essa estratégia, eu fornecia ao leitor condições para que ele se aproximasse do universo nativo, detalhando os diferentes usos de cada categoria em diferentes contextos.

Ao mesmo tempo, entretanto, era necessário estar atento para evitar o efeito de estabilização das categorias, que poderiam passar a ter um sentido referencial único para meu leitor. Esse problema é destacado por Herzfeld (2003, p. 113): se por um lado a recorrência de palavras em ucraniano em meu texto servia "para lembrar ao leitor que nenhuma tradução é perfeita e que o autor está atento a possíveis erros de interpretação", havia um risco de que, "após o leitor [ter sido] 'treinado' acerca do significado do termo ao vê-lo usado em um conjunto de contextos diagnósticos, suas ocorrências posteriores [passassem a ser] rotinizadas e consideradas como semanticamente estáveis".

Tal problemática ficava clara nas ocorrências dos termos svídomich [свідоміш] е pobójnei [побожний], tradutíveis em um primeiro momento por "consciente" e "devoto". Se em alguns casos seu significado era próximo daquele transmitido pelas palavras em português, em outros casos eles eram utilizados para falar de algo diferente: o imigrante. Paulo Muzeka (1936), por exemplo, utilizou esses termos para falar dos seus companheiros que não se rebelavam contra as autoridades brasileiras, mesmo ao serem confrontados com a fome ou a opressão. A "devoção" e a "consciência" confundiam-se aí com a obediência à autoridade, ampliando o espectro semântico emprestado a cada categoria: na visão de Muzeka (e de vários outros, como Pelep Kobren em um texto escrito em 1935), a revolta era vista como uma negação de um destino obrigatório de trabalho e submissão - e, em sua opinião, como um pecado. Já ao longo de meu trabalho de campo, percebi que as mesmas categorias denotavam quem era considerado de confiança em uma dada "colônia". $\mathrm{Na}$ colônia Tijuco Preto, por exemplo, acompanhei o caso do agricultor Jacó Nazarko, cuja família participava ativamente da paróquia (seu irmão, por exemplo, era presidente do conselho paroquial e que era, ele mesmo, assíduo nas missas e membro importante do Apostolado da Oração). Nazarko, considerado em sua comunidade como um homem pobójni, conseguiu comprar seu terreno para plantar fumo graças ao empréstimo de dona Tecla Krenda. ${ }^{8}$ Dona Tecla disse-me que o valor foi integralmente devolvido nos anos

6. No primeiro texto, o autor afirma que os homens precisam colocar ordem no universo, e que o fazem por meio de categorias classificatórias; a partir do segundo, tendo como interlocutores os filósofos neo-kantianos, Durkheim e seus seguidores desenvolveram estudos sobre cada uma das categorias clássicas do entendimento humano para demonstrar o caráter social de sua construção.

7. A palavra "colônia", no sul do Brasil, "é mais do que um referente territorial e socioeconômico: designa, de fato, a comunidade étnica" (Seyferth, 2003, p. 150, nota 8). De modo similar, a categoria "colono" nessa região é indissociável da imagem de um "camponês pequeno proprietário 'de origem'", sendo assim geralmente articulada a um qualificador étnico (Seyferth, 1996, p. 33, nota 7).

8. O dinheiro de Dona Tecla vinha da pensão de seu marido, que participou da Segunda Guerra Mundial como pracinha da FEB. 
seguintes; um colono que não participava das atividades da paróquia, contudo - e que, não sendo pobójni, jamais contaria com a confiança de dona Tecla -, contou-me essa história com ressentimento, espalhando o boato de que Nazarko "enganou a velhinha" e jamais lhe pagou um centavo.

As palavras pobójni e svídomiche são utilizadas, assim, dentro de uma estratégia de controle por parte de diferentes comunidades ucranianas, recompensando a participação na vida comunitária e punindo a não conformidade à rotina e aos valores religiosos locais. Mais do que simples qualificativos, elas são parte essencial das complexas dinâmicas sociais de cada agrupamento de falantes da língua ucraniana. Deste modo, elas devem ser compreendidas (e traduzidas) acompanhadas da contextualização de seu uso por parte dos falantes nativos, o que destaca sua instabilidade semântica e seus empregos pragmáticos.

\section{Os diferentes registros vocabulares e de escrita da língua ucraniana}

Um último tópico que abordaremos acerca da análise do uso da língua ucraniana pelos imigrantes dessa etnia e por seus descendentes diz respeito aos gêneros e técnicas de escrita de que eles lançam mão ao reconstruir sua realidade em sua língua nativa.

Em primeiro lugar, podemos destacar as implicações do emprego de diferentes registros de linguagem no momento da criação de um dado documento. Se compararmos os relatos acerca da migração disponíveis para análise, vemos que parte deles tem uma intenção memorialista: é o caso da autobiografia de Luca Morski (escrita em 1914 e citada em Morski [2000]) e do curto texto em que Pacevitch (1951) registra suas lembranças, afirmando ao mesmo tempo que,

agora, após 60 anos de vida no Brasil, tudo que nós, primeiros migrantes vivemos aqui parece um sonho. Nesse sonho eu vejo a floresta escura, tocos queimados e picadas estreitas. Os mais velhos morreram e deixaram seu lugar para os mais novos. É triste que nós tenhamos esquecido o que vivemos e o que fizemos, porque os mais jovens não se interessam muito sobre os primeiros anos de nossa vida no Brasil. É uma pena, porque tudo que há aqui agora, campos limpos e estradas - tudo é devido a nosso suor, e por vezes ao nosso sangue. Nas páginas desse jornal é possível deixar um pequeno fragmento de lembrança - e valeria a pena que se escolhesse alguém nas colônias e se procurasse aqueles que ainda estão vivos para dar testemunho, e com base em suas lembranças escrever a história de nossas colônias ucranianas no Brasil. Porque os anos passam - e a cada ano mais e mais de nós se vão, e sobram cada vez menos. (Pacevitch, 1951)

Pacevitch utiliza seu texto dentro de um gênero memorialista, evocando um passado distante que não deve ser esquecido. Esse registro discursivo contrasta com as longas citações que Kobren (1935) e Muzeka (1936) fazem da Bíblia em seus textos (Pratsia, 1935/1936), que em muitos momentos lembram um sermão religioso. Tanto os textos desses dois últimos migrantes quanto o de Hotsailiuk (Pratsia, 1924) objetivam não apenas registrar o passado, mas também defender e validar a atuação dos sacerdotes greco-católicos nas comunidades ucranianas, reinterpretando os diversos eventos da migração sob a linguagem religiosa e justificando implicitamente a obediência irrestrita à autoridade dos padres em cada colônia. Essa intenção é expressa explicitamente por Hotsailiuk, que, escrevendo sobre sua vinda ao Brasil em meio a uma crise de credibilidade das autoridades eclesiásticas greco-católicas no Brasil, ${ }^{9}$ afirma acerca dos primeiros anos de existência das colônias:

A morte estava em toda parte e famílias se desfaziam com maridos enterrando suas esposas, esposas enterrando seus maridos e todos enterraram ao menos um filho. Não havia alegria, esperança ou um sacerdote para oferecer conforto espiritual que desse forças e inspirasse as pessoas para continuar. Em seu sofrimento alguns maldiziam o Brasil. E quem sabe o que teria sido de nós se Deus em sua misericórdia não tivesse nos enviado um anjo dos céus na pessoa do padre Selvester Kizema? [...] As almas se elevaram, havia nova esperança após a chegada deste jovem padre e todos começaram a enxergar um futuro melhor. [...] Tudo mudou com a chegada de padre Selvester. [...] Os padres sofreram muito nesses primeiros anos e ainda assim eram nosso maior apoio, organizadores de escolas, igrejas e da vida comunitária. O povo ucraniano não esqueceu disso e permanece agradecido por tudo o que eles fizeram. (Pratsia, 1924)

A aceitação da autoridade dos padres é um pressuposto estruturante de vários dos relatos dos imigrantes ucranianos. Desde os primeiros anos de existência das colônias, quando eles escreviam cartas à

9. Nos anos 1920, os sacedotes greco-católicos foram alvo de uma intensa campanha de difamação por parte de membros da intelligentsia leiga no Brasil. A esse respeito, ver referência extraída por questão de anonimato. 
sua terra natal solicitado a vinda de sacerdotes greco-católicos, a linguagem utilizada expressava o desejo de colocar-se sob as ordens de uma autoridade religiosa. Conforme demonstrado em outro texto (Guérios, 2012, p. 133), esses imigrantes dirigiam-se aos sacerdotes utilizando o mesmo registro vocabular que era empregado na relação com os senhores feudais em sua terra de origem.

Outro elemento relativo à expressão escrita da língua ucraniana que surge em um dos relatos disponíveis diz respeito ao uso do alfabeto. Os ucranianos que vieram ao Brasil viviam em um ambiente multiétnico, sob a autoridade do Império Austro-Húngaro. Há vários séculos eles viviam em uma relação tensa com seus vizinhos poloneses. Isso se devia ao fato de os senhores feudais da região serem todos de origem polonesa - e, apesar de em sua maior parte as duas populações ter o mesmo perfil socioeconômico quando de sua vinda ao Brasil, a história de dominação polonesa contava como uma fonte de desentendimentos entre as duas etnias. As principais marcas da diferença étnica eram a religião e a língua: apesar de ambos os grupos serem católicos, os poloneses eram católicos romanos, enquanto os ucranianos que vieram ao Brasil eram católicos de rito oriental (uniatas); e apesar de o polonês e o ucraniano serem bastante próximos e de ocorrerem muitos empréstimos entre as duas línguas, as diferenças são facilmente perceptíveis para os nativos. Por fim, a língua polonesa utiliza o alfabeto latino, com algumas adaptações, enquanto a língua ucraniana utiliza o alfabeto cirílico.

É assim que o imigrante Teodor Pototskei, ao escrever uma carta para os ucranianos que foram aos Estados Unidos em 1997, sente-se na obrigação de pedir desculpas a seus conterrâneos não apenas porque tinha pouca formação e mal sabia escrever, mas especialmente porque, tendo frequentado uma escola polonesa, escrevia em "língua rutena mas em letras polonesas" - utilizando os caracteres latinos e não os cirílicos. Desse modo, o uso do alfabeto polonês não é neutro: qualquer transliteração implicava em proximidade com os poloneses, o que era malvisto.

Esse distanciamento compulsório entre as duas línguas está marcado em vários outros relatos: em certos trechos eu tinha dificuldade de entender a fala citada de alguns personagens; de fato, essas falas eram citadas em polonês - e escritas em alfabeto cirílico. $\mathrm{O}$ uso do polonês guarda um significado evidente para esses migrantes: quando a língua polonesa é acionada em algum depoimento, isso é feito sempre com a intenção de marcar que seu emissor era polonês; em todos esses casos, esse emissor era malvisto pelo autor do relato. Muzeka (1936), por exemplo, cita vários trechos de uma discussão que teve com o funcionário do correio em Prudentópolis quando quis enviar uma carta solicitando a vinda de sacerdotes: segundo ele, o funcionário dizia-lhe (em polonês) que eles não precisavam de um sacerdote ucraniano, pois havia padres poloneses disponíveis na colônia. As falas desse funcionário são sempre citadas em polonês por Muzeka. Já as falas de José Durski, comerciante que nasceu no Brasil como filho de um imigrante polonês e que falava apenas polonês, são citadas em ucraniano por Muzeka. A questão é que Durski, em sua opinião, "fez muito bem para nosso povo, dando-lhes trabalho, vendendo chácaras por dinheiro, e para quem não o tinha por trabalho. [...] Nossa gente até hoje lembra dele e lamenta que ele não esteja mais aqui, porque não fez mal a ninguém." Por esse motivo, Durski ganhou o direito de ter suas falas citadas por Muzeka em ucraniano.

Mais uma vez, foi necessário explicar ao leitor de minha tese todas essas diferenças na escrita e nas línguas utilizadas nos relatos dos imigrantes. Em se tratando da relação entre poloneses e ucranianos nas colônias, como ficou claro para mim desde o princípio de meu estudo nos arquivos, nenhuma escolha linguística ou de alfabeto era neutra; a tradução não poderia também deixar de contemplar essas diferenças. ${ }^{10}$

Por fim, cabe uma última palavra relativa à transliteração dos termos em ucraniano - assunto para o qual a resolução visou também à legibilidade para o leitor de língua portuguesa. Há uma norma oficial para a transliteração da língua ucraniana, a partir do alfabeto cirílico para o alfabeto latino. Contudo, ela foi elaborada tendo em vista o inglês como idioma de destino. Letras que existem apenas no alfabeto cirílico, como ч, Ш е щ, são transliteradas para o inglês a partir de uma aproximação de caráter fonético - respectivamente, como $c h$, sh e shh. Essa transliteração, no entanto, não faria sentido algum para os leitores de meu trabalho, publicado em língua portuguesa, gerando um estranhamento que em nada auxiliaria a leitura do texto. Optei assim por realizar uma aproximação fonética dessas letras - e, de fato, de todas as palavras ucranianas que nele apareceram -, em vez de seguir regras de transliteração que facilitariam, talvez, sua leitura para pessoas habituadas a elas, mas que dificultariam em muito sua legibilidade para o leitor que nunca trabalhou com línguas eslavas. Des-

10. Além do alfabeto, outra linguagem também teve sua importância na relação estabelecida entre poloneses e ucranianos nas colônias paranaenses: a arquitetura. O governo estadual construiu igrejas em várias colônias ocupadas por membros das duas etnias. As igrejas, contudo, seguiam o modelo latino, com a planta em forma de nave e torres góticas. Os poloneses utilizavam esse fato para tomar posse dos prédios: na colônia Santos Andrade, por exemplo, um organista polonês expulsou um cantor eclesial da igreja e jogou fora o tetrapod (símbolo da Ucrânia) do prédio. Seu argumento era que, como a igrejas não tinham as cúpulas bizantinas e a planta em forma de cruz, ela era uma kostéł (igreja polonesa), e não uma tsérkva (церква - igreja ucraniana). 
te modo, por exemplo, a palavra чорний (negro), bastante significativa para meu objeto de estudo, foi transcrita como tchórnei, de maneira aproximada a sua execução fonética para ouvintes de português - em vez de ser apresentada pela transliteração chornyj, utilizada para a língua inglesa.

\section{Conclusão}

Voltemos agora à nossa questão inicial: seria a tradução uma boa metáfora para a tarefa de um antropólogo?

Após minha experiência de trabalho de arquivo e de campo com os ucranianos, eu diria que a tentativa de traduzir de forma direta certas categorias nativas em outra língua esbarra necessariamente em um problema de incomensurabilidade. A tradução para o português de termos carregados de significação para os ucranianos só foi possível a partir de uma explicação detalhada dos diversos usos desses termos na vida cotidiana. Neste sentido, a tradução pareceria ser uma boa metáfora do trabalho do antropólogo, que para transmitir a experiência humana de um dado grupo deve lançar mão de uma série de contextualizações e explorações detalhadas das práticas cotidianas da sociedade que observa. Mesmo aí, no entanto, uma tarefa da tradução literária não serviria como analogia para a tarefa antropológica, visto que um tradutor ao contrário do antropólogo - deve achar uma forma concisa para transmitir a mensagem passada em uma língua para outra.

\section{Referências}

BENJAMIN, W. The task of the translator. In: VENUTI, L. (Ed.). The translation studies reader. London: Routledge, [1923]2000.

DURKHEIM, E. Les formes élémentaires de la vie religieuse. Le système totémique en Australie. $5^{\mathrm{eme}}$ éd. Paris: PUF, [1912]1968.

DURKHEIM, E.; MAUSS, M. De quelques formes primitives de classification. In: MAUSS, M. Oeuvres, v. 2. Paris: Minuit, [1903]1968. p. 13-89.

EVANS-PRITCHARD, Edward E. Social Anthropology: Past and Present. In : London: Faber and Faber, 1962.

GUÉRIOS, Paulo R. As condições sociais de produção das lembranças: um estudo da "memória" da imigração ucraniana ao Brasil. Mana, 14(2), p. 367-398, 2008.

A Imigração Ucraniana ao Paraná: Memória, identidade e religião. Curitiba: Editora da UFPR, 2012.

HERZFELD, M. The unspeakable in pursuit of
Já para a análise das questões de contato interétnico, a metáfora da tradução é efetivamente bastante falha. Para perceber certas dinâmicas sociais de contato entre ucranianos e brasileiros a partir da linguagem (observando o início da "pidginização" do ucraniano com o português), ou para traduzir o uso do polonês por parte dos ucranianos em seus relatos originais, foi necessário conhecer e descrever as dinâmicas de relação entre esses diferentes grupos, algo que exige uma análise cuidadosa de cada caso e de cada contexto - tarefa que não guarda semelhança alguma com a do tradutor, apesar de implicar em sérios problemas na própria tarefa de tradução. $\mathrm{O}$ mesmo ocorre com o esforço necessário para detectar como determinados padrões grupais poderiam infletir os discursos de cada imigrante em determinados sentidos, de forma consistente com esses mesmos padrões: a tradução que buscasse emprestar legibilidade ao leitor serviria apenas para tornar essa tarefa impossível (caso da tradução de Morski, citada acima), e, mais uma vez, uma reflexão literária acerca da tradução de pouco serviria no cumprimento desta tarefa de análise socioantropológica.

Ao mesmo tempo, no entanto, fica claro que uma reflexão acerca da tarefa de tradução é essencial para o antropólogo que trabalha com comunidades que utilizam línguas estrangeiras. Pois, como afirma Herzfeld (2003, p. 131), se "é correto interrogar a tradução como uma metáfora da etnografia, a presença de alguma forma de tradução na etnografia é uma pré-condição para sua existência".

the ineffable representations of untranslatability in ethnographic discourse. In: RUBEL, P.; ROSMAN, A. Translating cultures. Perspectives on translation and anthropology. Oxford: Berg, 2003.

HOTSAILIUK, A. Lembranças da primeira onda de emigração, Pratsia, dez 1924, p. 4. (Гоцайлюк, А. Спомини з перших хвиль еміграції. Праця, грудень 1924, p.4.)

KOBREN, P. 40 anos da imigração ucraniana ao Brasil. Lembranças do colono Pelep Kobren. (Кобрин, П. 40-ліття української еміграції в Бразилії. Спомини колоніста п. Пилипа Кобрина. Праця, 1936, Численні виданні.) MORSKI, J. P. Under the Southern Cross. A collection of accounts and reminiscences about the ukrainian immigration in Brazil, 1891-1914. Winnipeg: Watson \& Dwyer Publishing, 2000.

MUZEKA, P. 40 anos da imigração ucraniana ao Brasil. Colono Paulo Muzeka. Pratsia, 1936, vários números. 
(Музика, П. 40-ліття української еміграції в Бразилії. Колоніст п. Павло Музика. Праця, 1936, Численні виданні.)

OGLIARI, M. M. As condições de resistência e vitalidade de uma língua minoritária no contexto sociolinguístico brasileiro. Tese (Doutorado) - Departamento de Sociolinguística, UFSC, 1999.

PACEVITCH, I., Algumas de minhas lembranças, Pratsia, dez 1951, p.4. Пасевич, I. Дещо з моїх споминів. Праця, грудень 1951.

Pototskei, T. Carta do Brasil. Tzvirkun, ano 47, n. 204, p. 3-10 maio, 1992 [1897]. (Потоцкий, Т. Лист з Бразилії. Цвіркун, травень 1992 [1897], p. 47, ч. 204, с. 3-10).

Праця [Jornal Pratsia (“Trabalho”)] (publicou os relatos de Hotsailiuk, 1924; Kobren, 1935; Cheutchuk, 1936;
Muzeka, 1936).

SAYAD, A. El Ghorba: le méchanisme de reproduction de l'émigration. Actes de la Recherche en Sciences Sociales, n. 2, p. 50-66, mars 1975.

SEYFERTH, G. Etnicidade e cultura: a constituição da identidade teuto-brasileira. In: ZARUR, G. C. (Org.). Etnia e nação na América Latina. Washington: OEA, 1996. p. 17-36.

Estudo sobre reelaboração e segmentação da identidade étnica. In: SCOTT, P.; ZARUR, G. Identidade, fragmentação e diversidade na América Latina. Recife: Ed. UFPE, 2003. p. 147-183.

Цвіркун [Tzvirkun - "O Grilo" - jornal dos seminaristas basilianos] (publicou os relatos de Pototskei, 1897; Pacevitch, 1951).

\title{
Usos de la lengua ucraniana entre inmigrantes en Paraná y su traducción para el portugués
}

\section{Resumen}

\begin{abstract}
Durante mi investigación entre campesinos descendientes de ucranianos en el estado de Paraná, el aprendizaje de la lengua ucraniana (lengua eslava emparentada con el ruso) se impuso progresivamente como esencial para el desarrollo del trabajo. Si por un lado el dominio (aunque parcial) de la lengua hablada facilitó mi inserción en campo y el acceso a temáticas y a rituales familiares y religiosos, por otro el dominio del alfabeto cirílico y de la lengua escrita, permitió, a través del trabajo sobre los archivos de la etnia, tematizar: los significados políticos del uso de un determinado registro de vocabulario de la lengua ucraniana por parte de los inmigrantes que vinieron al Brasil; el significado de diversas categorías nativas y las lecturas que ellas posibilitan sobre la realidad vivida; la cuestión de la viabilidad de la traducción o de la necesidad de mantener un dado termo en su lengua original, así como de la contextualización de las categorías nativas; y las problemáticas relativas a la transliteración del alfabeto cirílico para el portugués.
\end{abstract}

Palabras clave: traducción cultural, ucranianos-Brasil, análisis del discurso.

\section{The uses of Ukrainian language among immigrant peasants and their descendants in Paraná and its translation into Portuguese}

\begin{abstract}
While completing my research amongst the descendants of Ukrainian peasants in the state of Paraná, learning the Ukrainian language (a Slavic language akin to Russian) became increasingly essential as my work unfolded. If, on the one hand, the mastery (even partial) of spoken language facilitated my entry into the field and my access to familiar and religious rituals and issues, on the other, my proficiency in reading in the Cyrillic alphabet and the Ukrainian written language allowed me, by working on ethnic archives to thematize: political injunctions of the uses of a given register of the vocabulary of the Ukrainian language by immigrants who came to Brazil; the meaning of various native categories and the readings made possible about lived realities; the question of the feasibility of translation or the need to keep a given term in its original language, as well as the contextualization of the native categories; and the issues concerning the transliteration of the Cyrillic alphabet into Portuguese.
\end{abstract}

Key words: cultural translation, Ukrainians-Brazil, discourse analysis.

Data de recebimento do artigo: 1/3/2013

Data de aprovação do artigo: 17/10/2013 